\title{
Os Usos do Tempo Livre entre Jovens de Classes Populares
}

\author{
Manoela Pagotto Martins Nodari ${ }^{1}$ \\ Edinete Maria Rosa \\ Celia Regina Rangel Nascimento \\ Valeschka Martins Guerra \\ Universidade Federal do Espírito Santo
}

\begin{abstract}
RESUMO - O presente estudo, de caráter quantitativo, pretendeu investigar aspectos relacionados ao tempo livre de jovens de classes populares. Participaram da pesquisa 291 jovens (53,3\% meninas), de 15 a 19 anos $(M=16,3 ; D P=1,09)$, estudantes de ensino médio em escolas públicas da Grande Vitória, ES. Os dados foram coletados através de questionário e analisados através do software SPSS. Os resultados apontaram, principalmente, para os diferentes fatores envolvidos nas formas de apropriação do tempo livre entre esses jovens, não relacionados estritamente à renda, mas também a aspectos como gênero, meio em que vivem, estilos de vida e grupos de que participam.
\end{abstract}

Palavras-chave: juventude, tempo livre, classe popular

\section{The Use of Free Time Among Working-Class Youth}

\begin{abstract}
This quantitative study investigated aspects related to working-class youth's free time. A total of 291 high school students from public schools in Vitória, ES, aged 15 to 19 years $(M=16.3 ; S D=1.09)$, participated in the survey $(53.3 \%$ girls). Data were collected through a questionnaire and analyzed using SPSS software. The results mainly indicated different factors involved in how these young people used their free time, which were related not only to income, but also to aspects such as gender, environment where they lived, lifestyles, and groups they belonged to.
\end{abstract}

Keywords: youth, free time, working-class

O interesse científico pela temática do tempo livre e lazer é relativamente recente. Como apontam Bonato, Sarriera e Wagner (2012), há um crescimento significativo das publicações que abordam o assunto nas últimas décadas e proliferam-se, no Brasil e no mundo, grupos de pesquisadores que têm se debruçado sobre questões que envolvem o tempo livre, a partir de diversas orientações e vertentes, interessados, principalmente, na forma como esse tempo se insere nas relações entre os indivíduos e grupos.

No Brasil, duas correntes teóricas principais têm exercido notável influência nos estudos a respeito da temática. A primeira delas é representada pelo francês Joffre Dumazedier (1973), considerado o criador da sociologia do lazer e com uma produção vastíssima a respeito do tema. $\mathrm{O}$ teórico define o lazer a partir da não-obrigatoriedade das ações nele realizadas e considera três funções básicas que caracterizam esse tempo: o descanso, a diversão e o desenvolvimento. Em seus estudos, recebe destaque uma visão do lazer essencialmente como elemento compensatório das tensões geradas no mundo do trabalho, o que acabou the rendendo críticas (Bonato et al., 2012; Franch, 2000; Padilha, 2006).

Sob outra perspectiva, Norbert Elias e Eric Dunning (1996) apontam o lazer como fenômeno fundamental para o viver social e ressaltam a busca pela excitação e o relativo descontrole das emoções como características principais

1 Endereço para correspondência: Prédio Professor Lídio de Souza, Centro de Ciências Humanas e Naturais, Universidade Federal do Espírito Santo, Av. Fernando Ferrari, 514, Goiabeiras, Vitória, ES, Brasil. CEP. 29.075-910.E-mail:manu_pagotto@yahoo.com.br que estão no cerne dessas atividades. Os autores definem com maior clareza as relações existentes entre os conceitos de lazer e tempo livre, sendo o tempo livre definido como o tempo liberado do trabalho ocupacional e o lazer, por sua vez, compreendendo as atividades de caráter recreativo que podem ser realizadas nesse período. Nesse sentido, o tempo livre é, então, por eles compreendido a partir de três categorias: (a) rotinas do tempo livre (beber, comer, limpar a casa, etc.); (b) atividades intermediárias de tempo livre (trabalhos comunitários, cursos, atividades religiosas, etc.); e, por fim, as (c) atividades recreativas (jogos de futebol, festas, reuniões de caráter formal e informal, viagens, etc.).

$\mathrm{Na}$ literatura, são encontradas diversas formas de classificar as atividades realizadas no tempo livre. Brenner, Dayrell e Carrano (2005) sugerem que elas sejam divididas em: atividades de lazer e entretenimento; atividades dentro de casa; atividades esportivas e atividades culturais. Franch (2000), por sua vez, apresenta diferentes classificações para apreender as diversas facetas que permeiam esse tempo: atividades individuais ou sociais; atividades realizadas dentro de casa e atividades de rua; e, ainda, atividades para matar, ocupar ou aproveitar o tempo. Outra classificação bastante corrente é a de Formiga, Ayrosa e Dias (2005) que dividem as atividades em: hedonistas, lúdicas e instrutivas.

No âmbito do tempo livre/lazer juvenil, os pesquisadores que se dedicam à temática (Abramo, 2005; Bonato et al., 2012; Brenner et al., 2005; Carrano, 2003; Franch, 2000; Marques, Dell'Aglio, \& Sarriera, 2009; Martins, Trindade, Menandro, \& Nascimento, 2014; Miranda, Filho, \& Santiago, 2014; Prates, 2012; Sarriera, Tatim, 
Coelho, \& Bucker, 2007; Sebenello, Keitel, \& Kleba, 2016 ) têm destacado essa dimensão como uma das vias mais frutíferas para se compreender as diversas vivências juvenis na contemporaneidade. São momentos fundamentais para o exercício de suas sociabilidades, para a elaboração de suas múltiplas identidades e, ainda, por propiciar o desenvolvimento de práticas próprias, ritos, simbologias e modos de ser que os diferenciem (Brenner et al., 2005).

Os usos que os jovens fazem de seu tempo livre têm muito a nos revelar: sobre sua relação com os contextos em que estão inseridos, sobre suas escolhas (ou falta delas), seus desejos, sonhos e projetos de vida. Contudo, quando falamos no tempo livre de jovens de baixa renda, duas linhas de pensamento principais vêm sendo usualmente exploradas nos estudos: (a) a ideia de um tempo ocioso, caracterizado pela falta de opções de escolha e, logo, em que não há muito que fazer; e também como (b) tempo propício ao risco, afinal, já que não há muitas perspectivas para o seu uso, torna-se mais "fácil" envolver-se em situações "erradas" e "perigosas". Como percebeu Franch (2010), em pesquisa com jovens da periferia de Recife, a expressão jovem de risco faz parte até mesmo do vocabulário dos próprios jovens, que dizem já estar acostumados com essa denominação, comumente utilizada nos programas que atuam em suas comunidades, nos grupos que participam ou nas reportagens apresentadas pela mídia. De modo geral, há uma tendência em se enxergar o tempo livre de jovens de classes populares sob uma ótica pessimista, ressaltando as carências que permeiam seu cotidiano, tais como, a falta de equipamentos de lazer adequados, a precariedade de seus espaços de convívio, a falta de laços afetivos com suas famílias, as baixas expectativas de futuro, etc. (Sebenello et al., 2016).

Tudo isso contribui para que se perpetuem visões reducionistas desses jovens, que os colocam a priori em uma condição de "problema" e quase sempre abordam o seu tempo livre sob um ponto de vista dicotômico: ora como oportunidade (quando ocupado de forma planejada e estruturada) ora como risco (quando distante de uma noção de controle), desconsiderando, assim, a diversidade de experiências que podem ser vivenciadas por esses jovens. Como explicam Bonato et al. (2012), estamos diante de um campo muito complexo para que possamos reduzi-lo a riscos ou oportunidades. Os autores apontam, então, para a necessidade de se investir em pesquisas que considerem as múltiplas variáveis que envolvem o tempo livre juvenil, buscando compreender não só os diversos sentidos que lhes são atribuídos como também o contexto sociocultural em que tais práticas se inserem.

Diante desse panorama, o presente estudo, de caráter quantitativo, buscou conhecer os usos do tempo livre entre jovens de classes populares e, para tal, realizou um levantamento das atividades de tempo livre que fazem parte do cotidiano desses jovens, seu acesso a meios digitais e a sua participação em grupos. Não é intenção desta pesquisa perpetuar paradigmas preestabelecidos a respeito dos jovens de camadas populares, mas permitir que se ampliem as possibilidades de se enxergar esses jovens. Nesse sentido, pretende-se discutir os resultados encontrados a partir dos diversos significados que lhes podem ser atribuídos, distanciando-se, assim, de uma visão pessimista que tem se naturalizado nas representações a respeito da temática.

\section{Método}

\section{Participantes}

A amostra foi composta por 291 jovens, sendo 155 do sexo feminino e 136 do sexo masculino, residentes, em sua maioria, em bairros de baixo nível socioeconômico, estudantes da $1^{\text {a }}$ a $3^{\text {a }}$ série do ensino médio em escolas públicas da Região Metropolitana da Grande Vitória, ES. Optou-se por investigar jovens frequentadores do ensino médio por entendermos que a permanência na escola traz reflexos importantes para seu desenvolvimento e acaba sendo percebida como uma característica protetiva em suas vidas.

Em relação à faixa etária, foram investigados jovens de 15 a 19 anos $(M=16,3 ; D P=1,09)$, sendo $24,4 \%$ com 15 anos; $34,7 \%$ com 16 anos; $24,4 \%$ com 17 anos; $13,1 \%$ com 18 anos; e 3,1\% com 19 anos. Do total de participantes, $49,8 \%(n=145)$ se declararam como pardos, $24,4 \%(n=71)$ se declararam brancos, $21 \%(n=61)$ se declararam negros e $4,5 \%(n=13)$ com outra identidade racial (amarelos, indígenas).

\section{Instrumento}

Foi adotado como instrumento para a coleta de dados a $2^{\mathrm{a}}$ versão do Questionário da Juventude Brasileira (Dell'Aglio, Koller, Cerqueira-Santos \& Colaço, 2011), elaborado para a segunda etapa do Estudo Nacional sobre Fatores de Risco e Proteção na Juventude Brasileira, vinculado à Associação Nacional de Pesquisa e Pós-Graduação em Psicologia (ANPEPP). O questionário é constituído por 77 questões de múltipla escolha em diferentes modelos (dicotômicas, múltiplas alternativas, formato Likert de cinco pontos, etc.) e aborda aspectos relacionados às temáticas de família, saúde, sexualidade, violência, preconceito, educação, lazer, acesso digital, autoestima, autoeficácia e perspectivas para o futuro (Dell'Aglio et al., 2011). No presente estudo, foram utilizados os dados referentes à caracterização dos jovens participantes, suas vivências de lazer e tempo livre, bem como seu acesso a meios digitais e participação em grupos.

\section{Procedimentos de Coleta de Dados}

Para a coleta de dados, foram sorteadas aleatoriamente escolas da rede pública da Região Metropolitana da Grande Vitória, ES. Inicialmente, a partir de cálculo amostral, estimou-se a participação de 350 jovens e um total de oito escolas investigadas. Contudo, após contato prévio com a coordenação das instituições sorteadas e apresentação dos objetivos do estudo, alcançou-se o número de seis escolas participantes e um total de 291 jovens.

Após aprovação da coordenação, os alunos foram contatados em sala de aula e convidados a participar da 
pesquisa, sendo garantida a voluntariedade da participação, o sigilo das informações pessoais e a possibilidade de desistência a qualquer momento. Os pais dos alunos que concordaram com a participação de seus filhos assinaram um Termo de Consentimento Livre e Esclarecido e os jovens assinaram um Termo de Assentimento.

Os questionários foram aplicados em sala de aula, de forma coletiva, por duas pesquisadoras acompanhadas por auxiliares treinados para aplicação do instrumento. As coletas tiveram duração média de 60 minutos. O projeto foi aprovado pelo Comitê de Ética da universidade sob o n. 281/10.

\section{Procedimentos de Análise de Dados}

Foram realizadas análises estatísticas dos dados coletados com o auxílio do software SPSS. Primeiramente, fez-se uma análise descritiva a fim de mapear as atividades de tempo livre dos jovens investigados, seu acesso a meios digitais e participação em grupos (médias, desvio-padrão, frequências e percentuais). Posteriormente, utilizou-se o teste do quiquadrado com a finalidade de verificar as possíveis diferenças no uso do tempo livre considerando as variáveis: sexo, renda e trabalho. O nível de significância adotado foi de $p<0,05$.

\section{Apresentação dos Resultados}

A tabela 1 apresenta dados relativos à caracterização dos participantes, com as porcentagens de repostas encontradas em relação às variáveis renda, itens que têm em casa, composição familiar e religião.

Observa-se que a maior parte da amostra possui renda mensal de, aproximadamente, um a três salários mínimos $(49,6 \%)$ e vive com os dois progenitores $(48,6 \%)$, em um arranjo clássico.

Em relação ao grau de escolaridade dos pais, a maioria possui ensino médio completo, sendo que os pais $(30,7 \%)$ apresentam uma leve vantagem em relação às mães $(29,2 \%)$. No que diz respeito ao trabalho, 34,7\% dos jovens investigados disseram estar trabalhando, atuando, principalmente, como office-boys, secretárias e profissionais de informática, etc. $(13,2 \%)$ ou ainda em comércio, lojas, mercados $(5,9 \%)$, sendo que somente $16,3 \%$ alegaram trabalhar com carteira assinada.
De modo a conhecer os usos do tempo livre entre os jovens investigados, perguntamos o que eles costumam fazer quando não estão estudando ou trabalhando - questão com múltiplas alternativas e que permitia mais de uma resposta. A opção Navegar na internet apareceu como uma de suas maiores preferências, seguida pelas opções Assistir TV e Ouvir ou tocar música como a segunda e terceira atividades mais realizadas, respectivamente. Entre os interesses de lazer menos frequentes aparecem Jogar/brincar e também Desenhar/pintar/artesanato (Tabela 2).

Tabela 2. Frequências e percentuais gerais de respostas por atividades de tempo livre

\begin{tabular}{lcc}
\hline \multicolumn{1}{c}{ Atividades } & $\begin{array}{c}\text { Frequência } \\
\text { (N) }\end{array}$ & $\begin{array}{c}\text { Porcentagem } \\
(\mathbf{\% )}\end{array}$ \\
\hline Navegar na internet & 239 & 84,5 \\
Assistir TV & 238 & 84,1 \\
Ouvir ou tocar música & 223 & 78,8 \\
Descansar & 174 & 78,8 \\
Cinema ou teatro & 151 & 61,5 \\
Passear & 150 & 53,4 \\
Namorar & 142 & 53,0 \\
Ir a festas & 135 & 50,2 \\
Ler livros, revistas... & 134 & 47,7 \\
Praticar esportes & 121 & 42,8 \\
Jogar/brincar & 107 & 37,8 \\
Desenhar/pintar/artesanato & 49 & 17,3 \\
\hline
\end{tabular}

Em relação ao uso da internet (atividade mais realizada entre os participantes), 92,8\% da amostra alegou ter acesso à rede, sendo que esse acesso se dá principalmente na própria casa $(81,4 \%)$, seguido de lan houses $(18,2 \%)$, escola $(13,5 \%)$, trabalho $(12 \%)$ e, com menor porcentagem, em outros locais $(6,9 \%)$, tais como, casa de amigos e/ou parentes ou até mesmo através do celular - que parece estar de fato inserido no cotidiano desses jovens, já que uma parcela expressiva da amostra (82,3\%) alegou possuir o aparelho, especialmente, no modelo pré-pago. Questionados sobre os motivos que os levam a utilizar a internet - questão de múltipla escolha, sendo possível assinalar mais de uma resposta - 93,5\% dos participantes alegaram que utilizam a rede para fazer trabalhos escolares, 91\% para se comunicar com amigos

Tabela 1. Caracterização dos participantes

\begin{tabular}{lcccc}
\hline \multicolumn{4}{c}{ Porcentagem entre as respostas válidas (\%) } \\
\hline \multirow{2}{*}{ Renda familiar } & Até 1 SM* & De 1 a 3 SM & De 3 a 5 SM & Mais de 5 SM \\
& 6,8 & 49,6 & 29,1 & 14,5 \\
Itens que têm em casa & TV & Geladeira & Rádio/som & Computador \\
& 99,3 & 98,9 & 87,9 & 84,1 \\
Composição familiar & Nuclear & Monoparental & Reconstituída & Outros \\
& 48,6 & 29,3 & 13,8 & 8,3 \\
Religião & Evangélica & Católica & Sem religião & Outras religiões \\
& & & (crê em Deus) & \\
\hline Nota *S.M. = Salário Mínimo & 43,4 & 32,4 & 18,3 & 12,0 \\
\hline
\end{tabular}

Nota. *S.M. = Salário Mínimo 
(através de facebook, msn, orkut, e-mail, etc.), também com frequência significativa aparecem as opções baixar músicas, jogos ou filmes $(79,8 \%)$, navegar em sites de seu interesse $(68 \%)$, jogar $(53,6 \%)$ e, em menor proporção, comprar coisas $(20,6 \%)$ e a produção de conteúdo, através da criação de blogs $(15,2 \%)$.

Foram realizadas, ainda, análises com a finalidade de verificar as possíveis diferenças no uso do tempo livre considerando as variáveis: sexo, renda e trabalho. No que diz respeito ao gênero, de um modo geral, os meninos e meninas participantes da pesquisa apresentaram preferências bastante similares. As diferenças significativas foram encontradas nas atividades Passear e Ler livros, revistas, quadrinhos com porcentagens mais altas para as meninas e Praticar esportes e Jogar/brincar com porcentagens mais altas para os meninos (Tabela 3).

Tabela 3. Frequencias e percentuais das atividades de tempo livre por sexo

\begin{tabular}{|c|c|c|c|}
\hline $\begin{array}{l}\text { Atividade } \\
\left.(\mathrm{N}=\mathbf{2 8 3})^{*}\right)\end{array}$ & $\begin{array}{c}\text { N }(\%) \\
\text { Meninos }\end{array}$ & $\begin{array}{c}\text { N }(\%) \\
\text { Meninas }\end{array}$ & $\chi^{2}(g l), p$ \\
\hline Passear & $60(21,2)$ & $90(31,8)$ & $04,01(1), \mathrm{p}<0,05$ \\
\hline Ler livros, revistas & $43(15,2)$ & $91(32,2)$ & $18,68(1), \mathrm{p}<0,05$ \\
\hline Praticar esportes & $83(29,3)$ & $38(13,4)$ & $45,12(1), p<0,05$ \\
\hline Jogar/brincar & $65(23,0)$ & $65(23,0)$ & $15,95(1), \mathrm{p}<0,05$ \\
\hline
\end{tabular}

Nota. *Número total de respostas na questão

Em um comparativo entre as atividades de lazer de jovens que trabalham e não trabalham, observaram-se porcentagens significativamente mais altas nas atividades Namorar, Ir a festas, Ler livros, revistas, quadrinhos e Desenhar/pintar/ artesanato entre os jovens que não trabalham (Tabela 4).

Tabela 4. Frequências e percentuais das atividades de tempo livre entre jovens que trabalham e não trabalham

\begin{tabular}{lllc}
\hline Atividade $(\mathbf{N}=\mathbf{2 8 0}$ *) & $\begin{array}{c}\text { N(\%) } \\
\text { Trabalham }\end{array}$ & $\begin{array}{c}\mathbf{N}(\%) \mathbf{\% a ̃ o} \\
\text { trabalham }\end{array}$ & $\chi^{2}(\boldsymbol{g l}), \boldsymbol{p}$ \\
\hline Namorar & $58(20,7)$ & $81(28,9)$ & $6,11(1), \mathrm{p}<0,05$ \\
Ir a festas & $56(20,0)$ & $78(27,9)$ & $5,80(1), \mathrm{p}<0,05$ \\
Ler livros, revistas & $38(13,6)$ & $94(33,6)$ & $3,78(1), \mathrm{p}<0,05$ \\
Desenhar/pintar... & $10(3,6)$ & $38(13,6)$ & $4,87(1), \mathrm{p}<0,05$ \\
\hline
\end{tabular}

Nota. *Número total de respostas na questão

Em relação à renda, as diferenças significativas aparecem nas opções Navegar na internet, Cinema ou teatro e Ir a festas, sendo que, quanto maior a renda familiar em salários mínimos, maior a frequência dessas atividades (Tabela 5).

Quanto à participação em grupos de lazer, uma parcela significativa da amostra $(49,1 \% ; n=143)$ alegou participar ativamente em algum tipo de grupo, sendo, em sua maioria, integrantes de grupos religiosos (18,9\%), seguidos pela participação em equipes esportivas $(18,2 \%)$, grupos musicais $(12,7 \%)$, dança e teatro $(8,9 \%)$ e, em menor grau, grupos de trabalho voluntário $(3,4 \%)$, grupos políticos $(2,4 \%)$, grêmios estudantis $(2,1 \%)$ e grupos de escoteiros $(0,7 \%)$.

\section{Discussão}

Os jovens investigados apresentaram participação significativa na maior parte das atividades que lhes foram apresentadas (Tabela 2), sendo que mais da metade da amostra alegou realizar pelo menos sete das 12 atividades propostas. Ao nos voltarmos para o perfil dessas atividades, observamos que elas se encaixam em diferentes classificações e, até mesmo, em mais de uma delas simultaneamente. A opção assistir $T V$, por exemplo, pode tanto ser uma atividade individual (quando se está assistindo sozinho) como social (quando todos da família se reúnem para assistir uma determinada programação); namorar pode ser uma atividade realizada tanto em casa como na rua, praticar esportes pode ser ao mesmo tempo algo lúdico e instrutivo e há, ainda, a atividade navegar na internet que possibilita a interação com diversos amigos através da rede. Assim, mais do que tentar enquadrar os usos do tempo livre em classificações, é importante perceber que as formas de apropriação desse tempo não são estáticas, lineares e nem sempre podem ser divididas em intervalos regulares. Elas podem sim, e muitas vezes acontecem, quase que de maneira simultânea, formando uma verdadeira "teia", em que uma interage com a outra. Basta olharmos para as diversas atividades que podem ser realizadas através de um aparelho celular, por exemplo: ao mesmo tempo em que se está escutando uma música, é possível enviar uma imagem para o(a) namorado(a) e interagir com os amigos nas redes sociais.

No que diz respeito às principais atividades de lazer realizadas pelos participantes (navegar na internet, assistir TV e ouvir ou tocar música), estas também têm aparecido de maneira significativa em outros estudos relacionados à temática, sendo as opções assistir TV e ouvir ou tocar música bastante correntes (Barros, Coscarelli, Coutinho \& Fonseca, 2002; Brenner et al., 2005; Esculcas \& Mota, 2005; Franch, 2000; Marques et al., 2009; Sarriera et al., 2007), enquanto o uso da internet aparece com maior frequência em estudos mais recentes (Martins et al., 2014; Miranda et al., 2014; Passarelli, Junqueira, \& Angeluci, 2014; Pfeifer, Martins, \& Santos, 2010; Spizzirri, Wagner, Mosmann, \& Armani, 2012; Viana et al., 2011).

Ressalta-se que as três atividades se desenvolvem prioritariamente no espaço doméstico. Para Castro e Abramovay (2002), o fato da maioria das práticas de lazer

Tabela 5. Frequências e percentuais das atividades de tempo livre por renda

\begin{tabular}{|c|c|c|c|c|}
\hline Atividade $(\mathrm{N}=114 *)$ & $\begin{array}{c}\mathbf{N}(\%) \\
\text { Até } 1 \text { SM }\end{array}$ & $\begin{array}{c}\text { N(\%) } \\
1 \text { a } 3 \text { SM }\end{array}$ & $\begin{array}{c}\text { N(\%) } \\
\text { Mais de } 3 \text { SM }\end{array}$ & $\chi^{2}(g l), p$ \\
\hline Navegar na internet & $1(0,9)$ & $45(39,5)$ & $47(40,3)$ & $31,20(3), p<0,05$ \\
\hline Cinema ou teatro & $3(2,6)$ & $25(21,9)$ & $36(31,6)$ & $09,45(3), \mathrm{p}<0,05$ \\
\hline Ir a festas & $2(1,8)$ & $21(18,4)$ & $33(28,9)$ & $11,71(3), \mathrm{p}<0,05$ \\
\hline
\end{tabular}


de jovens de baixa renda estarem circunscritas ao espaço da casa indica a falta de espaços de lazer e cultura em suas comunidades. Essa ideia é também defendida pelos autores Dimenstein et al. (2005) e Miranda et al. (2014), que destacam a necessidade de se ampliar as iniciativas públicas voltadas para essas comunidades, visando, principalmente, a construção de espaços recreativos em seus ambientes de convívio. Mesmo reconhecendo que os jovens de periferia contam com poucos espaços para sua recreação, Franch (2000) segue outra direção e aponta as casas como elementos importantes no âmbito do tempo livre juvenil, abrigando muitas atividades, que não necessariamente precisam ser solitárias ou carentes de interesse para os jovens. Segundo a autora, a lógica consumista que impera em nossa sociedade nos faz acreditar que ficar em casa é sinônimo de tédio e aborrecimento, o que não deve ser tomado como verdade. As casas podem se transformar, muitas vezes, em lugar de encontro social, seja para reunir os amigos, receber o(a) namorado(a), assistir um filme na TV, tocar algum instrumento musical, compartilhar o computador, etc. objetos que aparecem integrados ao contexto doméstico, servindo como suportes às práticas de sociabilidade e também como alternativas para o tempo livre.

Outro ponto importante está relacionado à característica de simultaneidade que permeia a prática dessas atividades. Em pesquisa americana realizada pela Forbes em 2012, constatou-se que $45 \%$ das pessoas que assistem TV estão manuseando alguma outra tela em paralelo, seja o computador ou o celular. No Brasil, pesquisa similar, realizada pela Interactive Advertising Bureau, apontou que $61 \%$ das pessoas fazem o mesmo (Araújo, 2012). Passarelli et al. (2014) chamam atenção para a multiconectividade dos jovens, que estão em constante interação com diversos meios e plataformas de comunicação de forma simultânea.

A redução progressiva de um tempo verdadeiramente livre de obrigações nos induz a acreditar que é preciso viver o máximo de experiências possíveis em um curto espaço de tempo. Além disso, estar sempre conectado a algum tipo de mídia significa estar integrado a uma dinâmica própria do mundo contemporâneo e a população jovem, em especial, quer fazer parte dessa dinâmica. A impressão é de que está sempre acontecendo alguma coisa, em algum lugar, que é preciso saber o que é.

Presença quase obrigatória nos lares, a televisão aparece em grande parte das pesquisas como uma das principais formas de apropriação do tempo livre entre os jovens (Barros et al., 2002; Bonato et al., 2012a; Franch, 2000; Marques et al., 2009; McHale, Updegraff, Kim, \& Cansler, 2009; Miranda et al, 2014; Oliveira, 2015; Sarriera et al., 2007). Em relação aos aspectos positivos e negativos proporcionados pela atividade, os estudos apresentam posições divergentes, com maior ênfase para a segunda opção. Para Franch (2000), o foco principal dessa atividade está na sua capacidade de promover reuniões familiares e encontros de amigos, seja para assistir uma novela, filme, jornal ou mesmo um jogo de futebol. Contudo, nem sempre a televisão é abordada como atividade com engajamento positivo. Em seu estudo, Vandewater, Bicham e Lee (2006) lamentam que grande parte dos jovens americanos percam tanto tempo com a televisão. Para os autores, o tempo gasto com a TV ocorre em detrimento de outras atividades, como, por exemplo, o contato com pais e parentes, a leitura e o engajamento em atividades criativas. Oliveira (2015), em pesquisa com jovens de classe média, encontrou correlação negativa entre a atividade assistir $T V$ e as perspectivas de futuro dos jovens, demonstrando ser uma atividade muito realizada por aqueles que apresentam menores perspectivas. Estudos apontam também o fato de essa atividade ocorrer com frequência de forma isolada e muitas vezes sem a supervisão dos pais, o que não favorece o desenvolvimento social dos jovens e pode gerar comportamentos antissociais (Mahoney \& Stattin, 2000; Sinha, Cnaan, \& Gelles, 2007).

A preferência pela atividade ouvir ou tocar música aparece com frequência nos estudos brasileiros (Barros et al., 2002; Brenner et al., 2005; Marques et al., 2009; Martins, 2014; Miranda et al, 2014; Oliveira, 2015; Pfeifer et al., 2010; Sebenello et al., 2016) e foi também encontrada em estudos europeus (Cloes, Ledent, Didier, Diniz, \& Piéron,1997; Santos, Gomes, Ribeiro, \& Mota, 2005; Telama, Naul, Nupponem, Richtecky, \& Vuolle, 2002). De modo geral, os estudos destacam o importante papel exercido pela música na construção das identidades juvenis e como forma de pertencimento a um grupo. Trata-se de uma das principais prioridades de consumo dos jovens, que muito mais do que apenas ouvir músicas, cultivam ídolos, adquirem pôsteres e revistas musicais, assistem programas, consomem camisetas, bolsas, etc. Nesse sentido, perpetua-se, no cenário musical contemporâneo, uma infinidade de bandas destinadas aos jovens e também produzidas por eles, reforçando ainda mais o papel da música como meio de autodefinição e como um dos componentes principais das culturas juvenis (Franch, 2000; Martins et al., 2014).

A utilização da internet, assim como a TV e a música, já figura como uma atividade cotidiana entre os jovens de classes populares (Miranda et al., 2014; Pfeifer et al., 2010; Spizzirri et al., 2012; Viana et al., 2011). Em pesquisa do instituto Data Popular, realizada em 2006, 56\% dos domicílios de bairros populares possuíam acesso à internet, hoje esse número tende a ser ainda mais expressivo. Estamos lidando com uma geração de jovens que cresce em um mundo marcado por um significativo desenvolvimento tecnológico. São jovens nativos da linguagem digital dos computadores, dos celulares e da internet, que longe de verem esses elementos como uma ameaça, consideram-nos como ambientes naturais em suas experiências cotidianas. Por esse motivo, são muitas vezes os próprios jovens que introduzem os aparatos digitais em suas casas e tendem a ter um desempenho superior que o dos adultos nesses aparelhos (Cabra-torres \& Marciales-vivas, 2009; Prensky, 2001; Spizzirri et al., 2012).

Estudos recentes apontam, ainda, que o maior acesso à rede entre jovens de baixa renda se deve, principalmente, a um processo de inclusão digital que vem ocorrendo em várias cidades, a partir, sobretudo, de subsídios governamentais que tem contribuído para baratear essa tecnologia e ampliar o acesso das classes menos favorecidas (Miranda et al., 2014; Pfeifer et al., 2010; Silveira, 2005; Spizzirri et al., 2012). Além disso, a progressiva redução nos preços dos computadores e celulares nos últimos anos gera não só uma rápida descartabilidade desses produtos, como também contribui para elevar as possibilidades de sua aquisição 
(Spizzirri et al., 2012). Vale ressaltar que, em pesquisa com jovens de classes populares, realizada por Marques et al. em 2009, a opção navegar na internet aparecia somente em nono lugar, como uma atividade realizada por $27,8 \%$ dos jovens investigados.

Ainda que se perceba uma ampliação do acesso entre as classes populares, como indicam os próprios resultados da presente pesquisa, há certas particularidades quanto às formas de consumo dessas mídias que precisam ser consideradas (Barros, 2009; Dutra-Thomé \& Koller, 2014; Yaccoub, 2011). Em estudo realizado com jovens de classe alta e classe popular no Rio Grande do Sul, Dutra-Thomé e Koller (2014) constataram que os jovens de classe alta apresentaram porcentagens significativamente maiores de acesso a bens como celulares de conta, TV a cabo e internet em casa e na escola se comparados aos de classes mais baixas. Entre os jovens aqui investigados, observa-se que o consumo de celulares é muito mais significativo nos modelos pré-pagos e que o acesso à internet ocorre, principalmente, em casa e em lan houses.

Como explica Barros (2009), muito mais do que simples artefatos tecnológicos, objetos como o computador e o celular possibilitam ao indivíduo de baixa renda inserir-se na sociedade, o que a autora denomina como consumo de pertencimento. Daí o grande interesse desses indivíduos em adquirir produtos eletrônicos, que os conferem uma sensação de inclusão e os fazem sair de uma situação de invisibilidade. Sarti (2003) destaca que os discursos da carência e da falta, tão comuns em relação às camadas populares, tendem a considerá-las automaticamente como classes não consumidoras, no entanto, elas são sim consumidoras, mas participam de outras formas dos circuitos de consumo. Desenvolvem-se, nesses grupos, mecanismos adaptados como tentativa de integrar-se à sociedade de consumo, assim, por exemplo, divide-se um ponto da internet entre várias casas de modo a barateá-la, adquirem-se celulares de uma mesma operadora ou com mais de um chip em busca de menores tarifas nas ligações, frequenta-se lan houses para acessar a internet, entre outros.

Em relação aos efeitos positivos proporcionados pela internet, os estudos apontam, principalmente, a ampliação das formas de interação dos pares e destacam que, cada vez mais, os jovens têm utilizado a rede para realizar diversas atividades de seu cotidiano: estudar, namorar, conhecer pessoas, ter acesso à informação e conhecimento, desenvolver habilidades e talentos, etc. (Marques et al., 2009; Passarelli et al., 2014; Spizzirri et al., 2012). Contudo, os autores apontam também que o fácil acesso a uma infinidade de conteúdos na rede pode trazer riscos e alertam para a necessidade de se regular e orientar a sua utilização e, ainda, incentivar o desenvolvimento de modos criativos de relacionamento com essa tecnologia (Downs, 2011; Marques et al., 2009).

Voltando-se para as diferenças de gênero nos usos do tempo livre entre os jovens investigados, observa-se uma predominância significativamente maior dos meninos em atividades desenvolvidas prioritariamente no ambiente da rua (praticar esportes e jogar/brincar), o que também aparece nos estudos de Franch (2000), Sarriera et al. (2007), Bonato et al. (2012) e Miranda et al. (2014). Franch explica que, principalmente para os meninos, que possuem maior liberdade para circular pelo espaço público, as ruas se constituem como espaços polivalentes, onde inúmeras atividades se desenvolvem. É o local para o encontro de amigos, paqueras, jogos de bola, etc., um espaço privilegiado para o lazer cotidiano. Cabe salientar, porém, que o avanço constante da violência tem restringido consideravelmente o uso desses espaços, impedindo que essas atividades se desenvolvam com maior frequência e por um número mais expressivo de jovens (Sebenello et al, 2016).

Em relação à preferência masculina pela prática esportiva, Gáspari e Schwartz (2001) argumentam que, em nossa sociedade, o esporte é culturalmente associado a determinadas características que se identificam com a masculinidade - competitividade, agressividade e prestígio pessoal. Complementando essa ideia, Melo, Giavoni e Tróccoli (2004) apontam que essa preferência pode ser entendida como um padrão socialmente esperado, já que os estereótipos sexuais de gênero, de certa forma, influenciam os comportamentos masculinos e femininos. Nesse sentido, ainda que se note uma maior participação feminina nesse universo nos últimos anos, a imagem do esporte vinculada ao comportamento masculino acaba afastando muitas mulheres de sua prática. Como exemplificam Souza e Altmann (1999), basta observarmos as quadras esportivas das escolas, que durante o período de recreio e horários livres são quase exclusivamente ocupadas pelos meninos. Outro ponto importante a ser considerado é o fato de o esporte ser utilizado nas políticas públicas como "principal arma" para tirar o jovem do risco, o que faz com que a prática esteja muito presente nos programas desenvolvidos em bairros populares, onde atraem, especialmente, os meninos dessas comunidades (Rodrigues \& Scarparo, 2012).

Passear e ler livros, revistas e quadrinhos foram as atividades que apresentaram porcentagens significativamente mais altas entre as meninas da amostra. Ler livros também aparece em outros estudos, tanto nacionais (Barros et al., 2002; Bonato et al., 2012; Carvalho \& Machado, 2006; Oliveira, 2015; Sarriera et al., 2007) como internacionais (Athenstaedt, Mikula, \& Bredt, 2009; McHale et al., 2009), como uma preferência feminina. Marques et al. (2009) ressaltam a importância dos momentos de leitura por neles estarem implícitos reflexão, conhecimento de si e desenvolvimento de habilidades intelectuais, sociais e afetivas. A opção passear, por sua vez, não é comumente encontrada em pesquisas com meninas de classe popular, que acabam, em sua maioria, desenvolvendo atividades circunscritas ao espaço doméstico, onde é possível exercer maior vigilância (Franch, 2000) e também pelo fato de ser uma atividade que quase sempre exige um maior investimento financeiro. Contudo, em pesquisa recente de Miranda et al. (2014), a atividade também apareceu como sendo mais significativa para meninas. Como explicam Sarriera et al. (2007), esses passeios, geralmente, ocorrem na própria comunidade, no bairro ou em praças e parques públicos. Autores como Franch (2000), Martins et al. (2014) e Sebenello et al. (2016) destacam, ainda, que um passeio muito comum entre os jovens é a visita à casa de amigos, uma importante forma de sociabilidade e de fortalecimento das relações de amizade, principalmente entre as meninas, ainda sob a forte tutela dos pais. 
Diferenças significativas no uso do tempo livre também foram encontradas entre jovens que trabalham e não trabalham. De modo geral, os jovens que não trabalham possuem mais tempo para usufruir de momentos de lazer e acabam tendo participação significativamente maior em algumas atividades, tais como namorar (o que exige certa dedicação de tempo ao namorado/a) e ir a festas (já que não há preocupação com jornadas de trabalho e/ou compromissos profissionais). Por outro lado, o fato de disporem de maior tempo livre parece também estar sendo utilizado como forma de aperfeiçoamento pessoal e desenvolvimento de habilidades para esses participantes, daí se dedicarem mais às atividades ler livros, revistas e quadrinhos e desenhar/ pintar/artesanato.

Esses dados corroboram, de alguma forma, o que foi encontrado em estudo que comparou a relação entre o trabalho e a vida escolar de jovens trabalhadores e nãotrabalhadores de várias cidades do país (Dutra-Thomé, Pereira, \& Koller, 2016). Os autores verificaram, em uma amostra de 7425 jovens, que aqueles que trabalhavam tiveram um engajamento escolar inferior aos jovens que não trabalhavam. Além disso, a partir dos resultados encontrados, pôde-se inferir que os jovens trabalhadores possuíam menos horas de sono e também menos tempo disponível para recreação e lazer, considerada uma importante dimensão para o seu desenvolvimento.

As diferenças encontradas em relação à variável renda indicam uma maior participação dos jovens com melhor poder aquisitivo em atividades culturais e recreativas e também no acesso à tecnologia. Yaccoub (2011), em pesquisa em um bairro popular do município de São Gonçalo-RJ, deixa claro que, mesmo se tratando de um local considerado de classe popular, é possível observar uma hierarquia interna no bairro, sendo alguns lugares e pessoas mais prestigiosos que outros. A autora pôde perceber formas de distinção e de legitimidade sendo construídas dentro do próprio grupo, pautadas, principalmente, nas diferenças entre os que podiam e não podiam comprar determinado objeto, ou ainda, entre aqueles que moravam no "pedaço bom" e os que moravam no "morro". Entre os jovens de nossa pesquisa, observamos que o poder aquisitivo um pouco melhor acaba sendo significativo para sua participação em determinadas experiências de lazer que estão imersas na lógica da sociedade de consumo: ir a festas, ao cinema, teatro, navegar na internet, dados similares aos encontrados por Dutra-Thomé e Koller (2014) em sua pesquisa com jovens de classe alta e classe popular. Tratase de atividades que, na maioria das vezes, demandam um maior investimento financeiro e acabam se tornando eventos raros no cotidiano de jovens com renda mais baixa. De forma geral, há nas cidades poucos espaços públicos para o lazer e os eventos culturais nem sempre contam com a abrangência adequada e acabam ficando ainda muito restritos aos grupos mais privilegiados, o que indica a necessidade de se investir na criação de políticas que ampliem as esferas públicas democráticas de cultura e lazer (Brenner et al., 2005; Miranda et al., 2014).

Outro dado importante diz respeito à participação expressiva dos jovens investigados em grupos. É no grupo que os jovens trocam ideias, constroem amizades, compartilham gostos, visões e estilos de vida. De acordo com Marques et al. (2009), o engajamento em atividades desenvolvidas em associações religiosas, projetos sociais ou mesmo na própria comunidade tem sido compreendido como favorecedor de um desenvolvimento positivo.

Franch (2000), por sua vez, alerta que é preciso ter cautela quando falamos nos grupos organizados por projetos sociais em comunidades de baixa renda, pois, para a autora, estes ainda se encontram muito atrelados à ideia de livrar os jovens do mundo do crime e acabam, muitas vezes, reduzindo-se a uma perspectiva de controle e ocupação do tempo. Contudo, ainda que apresentem problemas, Franch enfatiza que o papel desses projetos não pode ser completamente desprezado, afinal são eles, muitas vezes, que dão sentido à vida dos jovens e abrem-lhes um novo campo de possibilidades. Entre os jovens da amostra, destaca-se a participação em grupos religiosos $(18,9 \%)$ que vem sendo apontada na literatura como efetiva proteção (Amparo et al., 2008; Koenig, McCullough, \& Larson, 2001; Whitehead, Wilcox, \& Rostosky, 2001). Ao estudar aspectos relacionados à religiosidade e identidade positiva na adolescência, Marques, Cerqueira-Santos e Dell'Aglio (2011) concluíram que a participação dos jovens em comunidades religiosas parece prover fortes redes de apoio social e influenciar positivamente o seu desenvolvimento.

\section{Considerações Finais}

O presente estudo investiu em uma análise de diferentes fatores que influenciam as formas de apropriação do tempo livre entre jovens de baixa renda. Nesse sentido, buscou-se reconhecer as diversas características que permeiam suas atividades, entendendo que não só a condição econômica deve ser considerada como definidora das práticas no âmbito do tempo livre, mas também, que há outros aspectos envolvidos nesse processo, tais como gênero, meio em que vivem, gostos, estilos de vida, grupos de que participam, entre outros.

Dessa maneira, os resultados apontam algumas questões importantes que devem ser destacadas: primeiramente, a significativa participação da internet como uma importante forma de sociabilidade e interação dos grupos, inclusive na classe popular, como já aparece em outras pesquisas mais recentes, e também, o fato de que as atividades de tempo livre desses jovens não devem ser compreendidas de forma estática e linear, mas a partir dos diversos sentidos que lhes podem ser atribuídos.

Por fim, gostaríamos de ressaltar que estamos lidando com dados quantitativos, o que exige cautela em nossas interpretações, sendo, então, recomendável o emprego de outras técnicas metodológicas para maximizar a validade dos resultados. Contudo, ainda que existam limitações, este estudo contribui para literatura ao trazer elementos importantes presentes no tempo livre de jovens de classes populares e demonstra a importância da continuidade dessas pesquisas para que se ampliem diferentes perspectivas a respeito dessa categoria.

Os dados contribuem, ainda, para a criação e implantação de políticas públicas que de fato estejam integradas com as reais necessidades desses jovens. Mais do que ocupar 
um tempo considerado potencialmente perigoso, é preciso atuar nas potencialidades de cada realidade. É necessário distanciar-se de uma perspectiva de resolução de problemas e oferecer programas e ações que partam das demandas dos próprios jovens, que promovam a integração e fortalecimento dos grupos em que estão inseridos e, finalmente, que visem incentivar sua autonomia, protagonismo e criatividade.

\section{Referências}

Abramo, H. W. (2005). Condição juvenil no Brasil contemporâneo. In. H. W. Abramo \& P. P. M. Branco (Eds.), Retratos da juventude brasileira: Análises de uma pesquisa nacional (pp. 37-72). São Paulo: Fundação Perseu Abramo.

Amparo, D. M., Galvão, A. C. T., Alves, P. B, Brasil, K. T., \& Koller, S. H. (2008). Adolescentes e jovens em situação de risco psicossocial: Redes de apoio social e fatores pessoais de proteção. Estudos de Psicologia, 13(2), 165-174. http://dx.doi. org/10.1590/S1413-294X2008000200009

Athenstaedt, U., Mikula, G., \& Bredt, C. (2009). Gender role selfconcept and leisure activities of adolescents. Sex Roles, 60, 399-409. doi: 10,1007 / s11199-008-9543-y

Araújo, L. (2012, Julho). A caixa de pandora contemporânea. Especial Caros Amigos, pp. 06-08.

Barros, R., Coscarelli, P., Coutinho, M. F. G., \& Fonseca, A. F. (2002). $\mathrm{O}$ uso do tempo livre por adolescentes em uma comunidade metropolitana no Brasil. Adolescência Latinoamericana, 3(2). Retirado de http://ral-adolec.bvs.br/scielo.php?script=sci_ arttext\&pid $=$ s1414-71302002000200008\&lng=es\&nrm $=$ iso $\&$ tlng $=\mathrm{pt}$

Barros, C. F. P. (2009). Apropriação de tecnologias digitais e usos de celulares nas camadas populares. In Congresso Brasileiro de Sociologia (Ed.), Anais - CD-ROM. Rio de Janeiro: Sociedade Brasileira de Sociologia.

Bonato,T. N., Sarriera, J. C, \& Wagner, A.(2012). O lazer na adolescência. In J. C. Sarriera \& A. C. Paradiso (Eds.), Tempo livre e lazer na adolescência:Promoção de saúde, intervenção e pesquisa (pp. 97-123). Porto Alegre: Sulina.

Brenner, A. K, Dayrell, J., \& Carrano, P. (2005). Culturas do lazer e do tempo livre dos jovens brasileiros. In H. W. Abramo, \& P. P. M. Branco (Eds.), Retratos da juventude brasileira: Análises de uma pesquisa nacional (pp. 175-214). São Paulo: Fundação Perseu Abramo.

Cabra-torres, F., \& Marciales-vivas, G. P. (2009). Mitos, realidades y preguntas de investigación sobre los 'nativos digitales': Una revisión. Universitas Psychologica, 8(2), 323-338. Retirado de http://www.scielo.org.co/pdf/rups/v8n2/v8n2a03.pdf

Carrano, P. C. R. (2003). Juventudes e cidades educadoras. Rio de Janeiro: Vozes.

Castro, M. G., \& Abramovay, M. (2002). Jovens em situação de pobreza, vulnerabilidades sociais e violências. Cadernos de pesquisa, 16, 143-176. http://dx.doi.org/10.1590/S010015742002000200007

Cloes, M., Ledent, M., Didier, P., Diniz, J., \& Piéron, M. (1997). Pratique et importance das principales de loisiris chez des jeunes de 12 a 15 ans dans cinq pays europées. ADEPS, 159/160, 51-60. Retirado de http://hdl.handle.net/2268/29777
Dell'Aglio, D. D., Koller, S. H., Cerqueira-Santos, E., \& Colaço, V. F. R. (2011). Revisando o questionário da juventude brasileira: Uma nova proposta. In D. D. Dell'Aglio \& S. H. Koller (Eds.), Adolescência e juventude: Vulnerabilidade e contextos de proteção (pp. 260-269). São Paulo: Casa do psicólogo.

Dimenstein, M., Lima, E. B., Moura, A., Brito, M., Cardoso, R., \& Medeiros, V. (2005). Bases de apoio familiares e comunitárias como estratégia de enfrentamento à violência. Psico, 36(1), 55-63. Retirado de http://revistaseletronicas.pucrs.br/ojs/index. php/revistapsico/article/viewFile/1375/1075

Downs, C. (2011). Playing in a virtual bedroom: Youth leisure in the Facebook generation. In R. Jeanes \& J. Magee (Eds.), Children, youth and leisure (pp. 15-31). EUA: Leisure Studies Association.

Dumazedier, J. (1973). Lazer e cultura popular. São Paulo: Editora Perspectiva.

Dutra-Thomé, L., \& Koller, S. (2014). Emerging adulthood in brazilians of differing socioeconomic status: Transition to adulthood. Paidéia, 24(59), 313-322. http://dx.doi. org/10.1590/1982-43272459201405

Dutra-Thomé, L., Pereira, A. S., \& Koller, S. H. (2016). O desafio de conciliar trabalho e escola: Características sociodemográficas de jovens trabalhadores e não-trabalhadores. Psicologia: Teoria e Pesquisa, 32(1), 101-109. http://dx.doi.org/10.1590/010237722016011944101109

Elias, N., \& Dunning, E. (1996). Deporte y ocio en el proceso de la civilización. México: Fondo de Cultura Económica.

Esculcas, C., \& Mota, J. (2005). Actividade física e práticas de lazer em adolescentes. Revista Portuguesa de Ciências do Desporto, 5(1), 69-76. Retirado de http://www.fade.up.pt/rpcd/_arquivo/ artigos_soltos/vol.5_nr.1/1.07.carlos_esculcas.pdf

Formiga, N. S., Ayroza, I., \& Dias, L. (2005). Escala das atividades de lazer: construção e validação em jovens. Revista de Psicologia da Vetor Editora, 6(2), 71-79. Retirado de http://pepsic.bvsalud.org/scielo.php?script=sci_arttext\&pid $=\mathrm{S} 1676-73142005000200009$

Franch, M. (2000). Tardes ao léu: Um ensaio etnográfico sobre o tempo livre entre jovens de periferia (Dissertação de Mestrado). Universidade Federal de Pernambuco, Recife. Retirado de http://www.bdae.org.br/dspace/bitstream/123456789/1967/1/ tese.pdf

Franch, M. (2010). Tempos na contramão: Sentidos e usos do tempo entre "adolescentes de risco" na cidade de Recife. In Fazendo Gênero 9: Diásporas, diversidades, deslocamentos (Ed.), Anais eletrônicos (pp. 01-08). Santa Catarina: Universidade Federal de Santa Catarina. Retirado de http:// www.fazendogenero.ufsc.br/9/resources/anais/1278295974_ ARQUIVO_temposnacontramao.pdf

Gáspari, J. C., \& Schwartz, G.M. (2001). Adolescência, esporte e qualidade de vida. Motrix, 7(2), 107-113. Retirado de http:// www.rc.unesp.br/ib/efisica/motriz/07n2/gaspari.pdf

Instituto Data Popular. (2006). O mercado da base da pirâmide do Brasil. Retirado de www.datapopular.com.br

Koenig, H. G., McCullough, M. E., \& Larson, D. B. (2001). Handbook of religion and health. Oxford: Oxford University Press.

Mahoney, J. L., \& Stattin, H. (2000). Leisure activities and adolescent antisocial behavior: The role of structure and social context. Journal of Adolescence, 1(2), 44-53. doi: 10,1006 / jado.2000.0302 
Marques, L. F., Dell'Aglio, D. D., \& Sarriera, J. (2009). O tempo livre na juventude brasileira. In R. M. C. Libório \& S. H. Koller (Eds.), Adolescência e juventude: Risco e proteção na realidade brasileira (pp. 79-106). São Paulo: Casa do psicólogo.

Marques, L. F., Cerqueira-Santos, E., \& Dell'Aglio, D. D. (2011). Religiosidade e identidade positiva na adolescência. In D. D. Dell'Aglio \& S. H. Koller (Eds.), Adolescência e juventude: Vulnerabilidade e contextos de proteção (pp. 78-108). São Paulo: Casa do psicólogo.

Martins, M. P., Trindade, Z. A., Menandro, M. C. S., \& Nascimento, C. R. R (2014). Representações sociais e vivências de lazer na juventude. Psicologia e Saber Social, 3(1), 41-54. Retirado de http://www.e-publicacoes.uerj.br/index.php/psi-sabersocial/ article/view/12202/9501

McHale, S. M., Updegraff, K. A., Kim, J., \& Cansler, E. (2009). Cultural orientations, daily activities, and adjustment in Mexican American youth. Journal of Youth Adolescence, 38, 627-641. doi: 10,1007 / s10964-008-9321-8

Melo, G. F., Giavoni, A., \& Tróccoli, B. T. (2004). Estereótipos de gênero aplicados a mulheres atletas. Psicologia: Teoria e Pesquisa, 20(2), 251-256. http://dx.doi.org/10.1590/S010237722004000300006

Miranda, L. L., Filho, J. A., \& Santiago, M. V. (2014). A relação lazer e mídia entre adolescentes e jovens de escolas públicas em Fortaleza/CE. Psicologia Argumento, 32(79), 29-43. doi: 10.7213/psicol..argum.32.s02.AO03

Oliveira, E. F. (2015). Vivências de lazer e tempo livre: Estudos com jovens de classe média (Dissertação de Mestrado). Programa de Pós-Graduação em Psicologia, Universidade Federal do Espírito Santo, Vitória.

Padilha, V. (2006). Dialética do lazer. São Paulo: Cortez.

Passarelli, B., Junqueira, A. H., \& Angeluci, A. C. B. (2014). Os nativos digitais no Brasil e seus comportamentos diante das telas. Matrizes, 8(1), 159-178. http://dx.doi.org/10.11606/ issn.1982-8160.v8i1p159-178

Pfeifer, L. I., Martins, Y. D., \& Santos, J. L. (2010). A influência socioeconômica e de gênero no lazer de adolescentes. Psicologia: Teoria e Pesquisa, 26(3), 427-432. Retirado de http://www.scielo.br/pdf/ptp/v26n3/a05v26n3.pdf

Prates, M. A. (2012). Conhecer, explorar e desenvolver atividades para o tempo livre: Um jeito próprio de ver a vida. In J. C. Sarriera \& A. C. Paradiso (Eds.), Tempo livre e lazer na adolescência: Promoção de saúde, intervenção e pesquisa (pp. 61-95). Porto Alegre: Sulina.

Prensky, M.(2001). Digital natives, digital immigrants. On the Horizon, 9(5), 1-6. doi: http://dx.doi.org/10.1108/10748120110424816

Rodrigues, A. L., \& Scarparo, H. B. (2012). O uso do esporte na ocupação do tempo livre na juventude: Subsídios para uma reflexão crítica. In J. C. Sarriera \& A. C. Paradiso (Eds.), Tempo livre e lazer na adolescência: promoção de saúde, intervenção e pesquisa (pp. 189-201). Porto Alegre: Sulina.

Santos, M. P., Gomes, H., Ribeiro, J. C., \& Mota, J. (2005). Variação sazonal na atividade física e nas práticas de lazer de adolescentes portugueses. Revista Portuguesa de Ciencias do Desporto, 5(2), 192-201. Retirado de http://www.scielo.mec.pt/scielo. php? script=sci_abstract\&pid=S1645-05232005000200008

Sarriera, J. C., Tatim, D. C., Coelho, R. P., \& Bucker, J. (2007). Uso do tempo livre por adolescentes de classe popular. Psicologia: Reflexão e Crítica, 20(3), 361-367. http://dx.doi.org/10.1590/ S0102-79722007000300003
Sarti, C. A. (2003). A familia como espelho: Um estudo sobre a moral dos pobres. São Paulo: Cortez.

Sebenello, D. C., Keitel, L., \& Kleba, M. E. (2016). Práticas de lazer e espaços públicos de convivência como potência protetiva na relação entre juventude e risco. Revista Katálysis, 19(1), 53-63. doi: 10.1590/1414-49802016.00100006

Silveira, S. A. (2005). Inclusão digital, software livre e globalização contra hegemônica. Parcerias Estratégicas, 20, 421- 446. Retirado de http://www.cgee.org.br/arquivos/p_20_1.pdf

Sinha, J. W., Cnaan, R. A., \& Gelles, R. J. (2007). Adolescent risk behaviors and religion: Findings from a national study. Journal of Adolescence, 30(2), 231-249. doi: 10.1016/ j.adolescence.2006.02.005

Souza, E. S., \& Altmann, H. (1999). Meninos e meninas: Expectativas corporais e implicações na educação física escolar. Cadernos CEDES, 19(48), 52-68. Retirado de http:// www.scielo.br/pdf/ccedes/v19n48/v1948a04

Spizzirri, R. C., Wagner, A., Mosmann, C. P., \& Armani, A. B. (2012). Adolescência conectada: Mapeando o uso da internet em jovens internautas. Psicologia Argumento, 30(69), 327-335. Retirado de http://132.248.9.34/hevila/ Psicologiaargumento/2012/vol30/no69/13.pdf

Telama, R., Naul, R., Nupponen, N., Richtecky, A., \& Vuolle, P. (2002). Physical fitness, sporting lifestyles and olimpic ideals: Cross cultural studies on youth sport in Europe. Schorndorf: Verlag Karl Hofmann.

Vandewater, E. A., Bickham, D. S., \& Lee, J. H. (2006). Time well spent? Relating television use to children's free time activities. Pediatrics, 117(2), 181-191. Retirado de http://pediatrics. aappublications.org/content/117/2/e181

Viana, D. M., Rodrigues, P. B., Araujo, I.C., Khouri, M. M., Mirando, L. L., \& Colaço, V. F. (2011). Juventude, escola e mídia: Problematizando a (in) acessibilidade das mídias para a construção crítica dos processos de ensino-aprendizagem na rede pública de educação. Revista Ibero-Americana de Estudos em Educação, 6, 01-15. Retirado de http://seer.fclar.unesp.br/ iberoamericana/article/view/4797/4067

Whitehead, B. D., Wilcox, B. L., \& Rostosky, S. S. (2001). Keeping the faith: the role of religion and faith communities in preventing teen pregnancy. Washington, DC: National Campaign to Prevent Teen Pregnancy.

Yaccoub, H. (2011). A chamada “nova classe média". Cultura material, inclusão e distinção social. Horizontes Antropológicos, 36, $197-$ 231. http://dx.doi.org/10.1590/S0104-71832011000200009

Recebido em 24.06.2014

Primeira decisão editorial em 12.08.2016

Aceito em 12.08.2016 